Pesq. Vet. Bras. 29(5):428-430, maio 2009

\title{
Queilite angular traumática em eqüinos associada à ingestão de Panicum maximum ${ }^{1}$
}

\author{
José Diomedes Barbosa ${ }^{2 *}$, Tatiane Teles Albernaz ${ }^{2}$, Gabriela Riet-Correa², \\ Valíria Duarte Cerqueira², Susiane de Oliveira Soares ${ }^{2}$, Karinny Ferreira \\ Campos $^{2}$, Carlos Magno Chaves Oliveira ${ }^{2}$ e Marcos Dutra Duarte ${ }^{2}$
}

\begin{abstract}
Barbosa J.D., Albernaz T.T., Riet-Correa G, Cerqueira V.D., Soares S.O., Campos K.F., Oliveira C.M.C. \& Duarte M.D. 2009. [Angular cheilitis in horses associated with ingestion of Panicum maximum.] Queilite angular traumática em eqüinos associada à ingestão de Panicum maximum. Pesquisa Veterinária Brasileira 29(5):428-430. Central de Diagnóstico Veterinário, Faculdade de Medicina Veterinária, Universidade Federal do Pará, Campus Castanhal, Rua Maximino Porpino da Silva 1000, Castanhal, PA 68740-080, Brazil. E-mail: diomedes@ufpa.br

A condition with enlargement of the oral cleft in horses was studied. The enlargement of varied extension was uni or bilateral. The cheek mucosa of the labial commissure showed slight erosions. During chewing there was loss of small amounts of grass and saliva through the oral cleft. The affected horses were in good nutritional condition. Histopathological studies of tissues obtained by biopsia, revealed a superficial epidermitis. The pastures consisted of Panicum maximum grass (varieties Tanzânia, Mombaça, Tobiatã and Colonião) which was mature, tall, lignified, with leaves of cutting edges. Based on epidemiological, clinical and histopathological data, it was concluded that the lesions were caused by the hard grass, favored by the way horses pull the tall grass and chew it.

INDEX TERMS: Angular cheilitis, labial commissure, oral cleft, traumatic lesion, horses, Panicum maximum.
\end{abstract}

RESUMO.- Uma condição com aumento da fenda bucal de eqüinos por lesão na comissura labial foi estudada. Este aumento tinha extensão variável e era uni ou bilateral. Na mucosa da bochecha da comissura labial exposta havia pequenas erosões. Durante a mastigação havia perda de pequena quantidade de capim e saliva pela fenda bucal aumentada. Os animais apresentavam bom estado nutricional. O exame histopatológico de tecido retirado da comissura labial revelou epidermite superficial. Nas quatro propriedades onde se verificou o problema, constatou-se que os eqüinos eram mantidos em sistema extensivo de criação em pastagem de Panicum maximum

\footnotetext{
${ }^{1}$ Recebido em 9 de janeiro de 2009.

Aceito para publicação em 24 de janeiro de 2009.

Este trabalho recebeu apoio do programa Instituto do Milênio (Proc.420012/2005-2).

${ }^{2}$ Central de Diagnóstico Veterinário da Faculdade de Medicina Veterinária, Universidade Federal do Pará, Campus Castanhal, Rua Maximino Porpino da Silva, 1000, Centro, Castanhal, PA, 68740-080, Brasil. *Autor para correspondência: diomedes@ufpa.br
}

(variedades Tanzânia, Mombaça, Tobiatã e Colonião), com folhas maduras, altas, lignificadas e de bordos cortantes. De acordo com os dados epidemiológicos, com os achados clínicos e histopatológicos, concluí-se que essas lesões foram causadas pela ação cortante das foIhas de Panicum maximum, associada à forma de apreensão da pastagem alta e mastigação pelos eqüinos.

TERMOS DE INDEXAÇÃO: Queilite angular, comissura labial, fenda bucal, lesão traumática, "boca rasgada", eqüinos, Panicum maximum.

\section{INTRODUÇÃO}

Tem sido observados, nos Estados do Maranhão e Pará, casos de lesões na comissura labial em eqüinos, conhecidos por "boca rasgada", caracterizada pelo aumento da fenda bucal. O presente estudo teve o objetivo de estudar a lesão e identificar os fatores epidemiológicos responsáveis.

\section{MATERIAL E MÉTODOS}

Foram visitadas quatro propriedades, no período de 20052008, uma localizada no Estado do Maranhão e as de- 

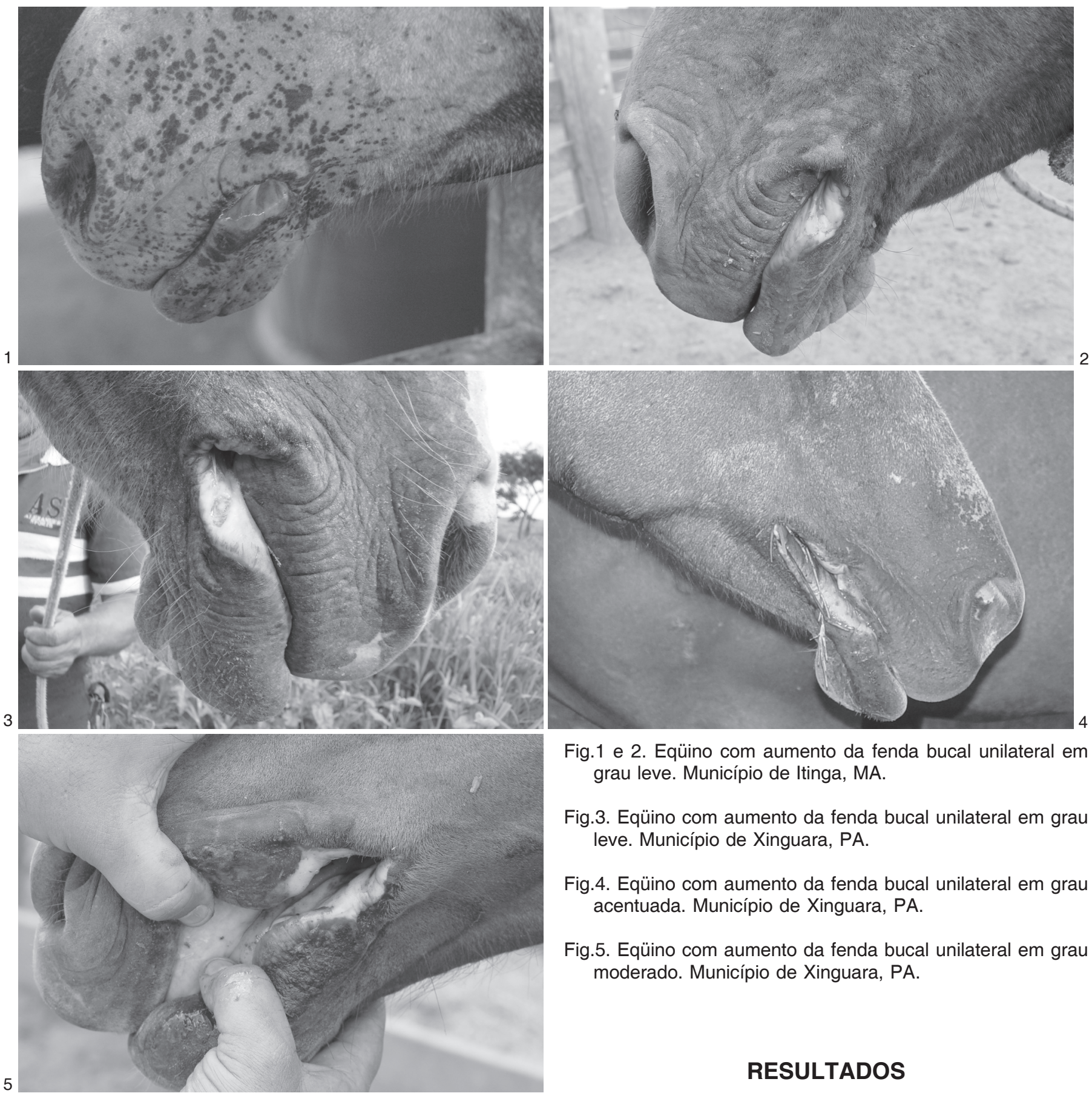

Fig.1 e 2. Eqüino com aumento da fenda bucal unilateral em grau leve. Município de Itinga, MA.

Fig.3. Eqüino com aumento da fenda bucal unilateral em grau leve. Município de Xinguara, PA.

Fig.4. Eqüino com aumento da fenda bucal unilateral em grau acentuada. Município de Xinguara, PA.

Fig.5. Eqüino com aumento da fenda bucal unilateral em grau moderado. Município de Xinguara, PA.

\section{RESULTADOS}

O exame clínico dos eqüinos afetados, nas quatro propriedades, revelou que a fenda bucal estava aumentada em

mais no sudeste do Estado do Pará. Foram examinados clinicamente 20 eqünos afetados. Através do exame da boca determinou-se o lado comprometido, a natureza e a extensão da lesão na comissura labial. As mesmas foram classificadas em leve (com extensão de até $2 \mathrm{~cm}$ ); moderada (de $3-5 \mathrm{~cm}$ ) e acentuada (acima de $5 \mathrm{~cm}$ ). Em dois animais foram realizadas biopsias da comissura labial lesionada, para realização de exames histopatológicos. Foram inspecionadas as pastagens onde os animais eram mantidos. sentido caudal. Havia leve exposição da mucosa da bochecha com pequenas erosões. Durante a mastigação havia perda de pequena quantidade de capim e saliva pela fenda bucal aumentada. Os animais afetados nas quatro propriedades apresentavam bom estado nutricional.

Na propriedade localizada no Estado do Maranhão, de oito eqüinos, quatro apresentavam lesão na comissura labial, sendo que um animal apresentava lesão acentuada e três, lesões leves (Fig.1-2), todas unilaterais. Em um 

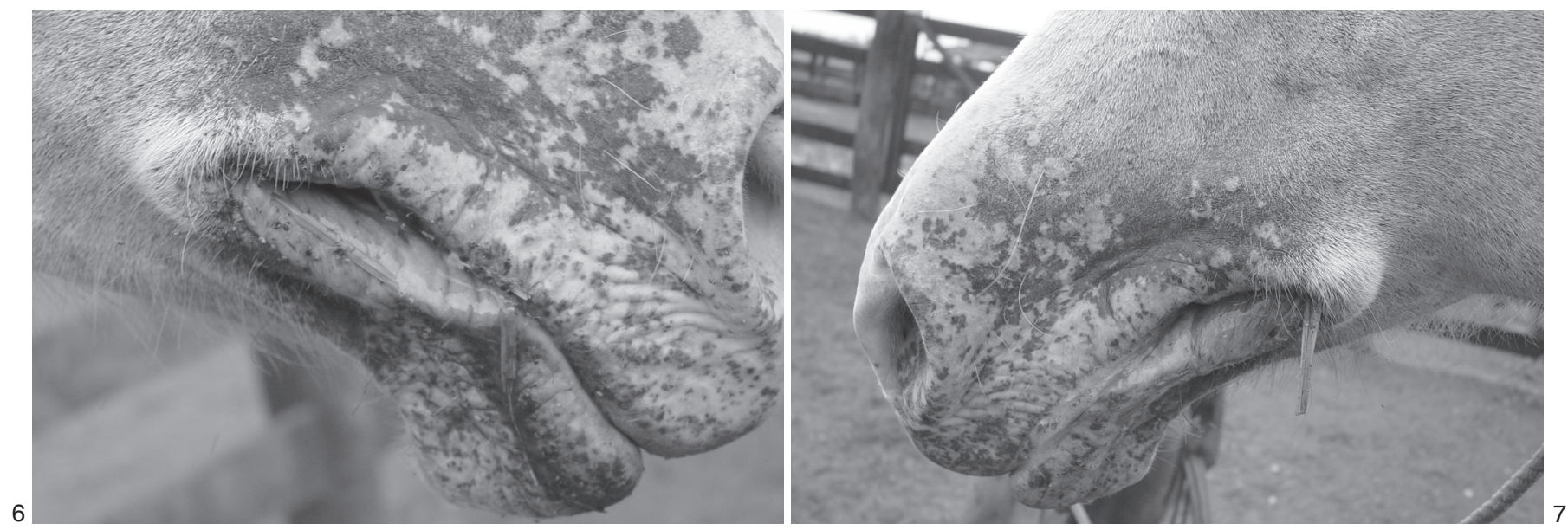

Fig.6 e 7. Eqüino com aumento da fenda bucal bilateral em grau acentuado. Município de Xinguara, PA.

destes animais foi realizada biopsia da comissura labial lesionada para exame histopatológico.

Em uma das propriedades localizadas no sudeste do Pará (município de Xinguara), de um rebanho de 300 eqüídeos, a maioria muares, todas as 22 éguas estavam afetadas, das quais 14 foram examinadas. No exame da cavidade oral observou-se que quatro animais apresentavam lesão apenas no lado direito - três leves (Fig.3) e um acentuada (Fig.4), quatro apresentavam lesão apenas no lado esquerdo (leves) e seis apresentavam lesões em ambos os lados - um com lesões leves em ambos os lados, um com moderada (Fig.5) no lado direito e leve no esquerdo, dois com lesões acentuadas no lado direito e moderada no esquerdo e dois com lesões acentuadas em ambos os lados (Fig.6-7). Em um destes animais foi realizada biópsia da comissura labial lesionada para exame histopatológico.

Nas duas propriedades restantes, localizadas no sudeste do Pará (municípios de Rondon do Pará e Abel Figueiredo) foram observados um caso em cada uma, nos únicos eqüinos existentes. Um apresentava lesão bilateral e o outro unilateral, todas com intensidade moderada.

Nas quatro propriedades em que foi realizado o presente estudo, constatou-se que os eqüinos eram mantidos em sistema extensivo de criação, em pastagens de Panicum maximum, cultivares Tanzânia, Mombaça, Tobiatã, no município de Xinguara, e de Colonião nos demais. Tratava-se de pastagens maduras, altas e com as folhas lignificadas e cortantes.
Ao exame histopatológico observou-se uma epidermite superficial.

\section{DISCUSSÃO E CONCLUSÃO}

Em relação à lesões da comissura labial, encontramos na literatura uma alteração comparável ao observada nos eqüinos, a queilite angular no homem, um processo inflamatório localizado no ângulo da boca, que entre outras, pode ter como causa fatores mecânicos (Pennini et al. 2000).

Inicialmente levantou-se a hipótese que as lesões na comissura labial dos eqüinos fossem causadas pelo freio bucal, utilizado para o controle do animal durante o trabaIho. Porém verificou-se que animais que não pastavam em Panicum maximum e usavam freio não apresentavam essas lesões e animais que não usavam freio, mas que pastavam Panicum maximum, apresentavam as lesões.

Pelos dados epidemiológicos, achados clínicos e histopatológicos, conclui-se que os eqüinos, devido a sua maneira de apreensão do capim alto, puxando-o pelos lados da boca e durante a mastigação, quando as folhas são puxadas para dentro da cavidade oral, sofrem continuamente pequenas lesões na comissura labial em virtude da ação traumatizante das folhas de Panicum maximum.

\section{REFERÊNCIAS}

Pennini S.N., Rebello P.F.B. \& Silva M.R. 2000. Jornal Brasileiro de Medicina 78(6):104-110. 